Saudi Journal of Humanities and Social Sciences

Abbreviated Key Title: Saudi J Humanities SocSci

ISSN 2415-6256 (Print)|ISSN 2415-6248(Online)

Scholars Middle East Publishers, Dubai, United Arab Emirates

Journal homepage: https://saudijournals.com

Original Research Article

\title{
Impact of Stress on Mental Health among Youth: A Study of Madhubani District, North Bihar, India
}

Ganga Prasad ${ }^{1 *}$, Anis Ahmad ${ }^{2}$

${ }^{1}$ Assistant Professor, Department of Psychology, Jagdish Nandan College (A constituent unit of L. N. M. U.), Madhubani - 847211, India

${ }^{2}$ Professor, University Department of Psychology, L. N. Mithila University, Darbhanga - 846 004, India

DOI:10.36348/sjhss.2020.v05i11.004| Received: 04.11.2020| Accepted: 17.11.2020| Published: 23.11 .2020

*Corresponding author: Ganga Prasad

\section{Abstract}

The present study was aimed at studying the impact of stress on mental health among youth with reference to Madhubani district of North Bihar, India. This study was conducted to assess the levels of mental health among youth and the relationship of the mental health with stress. Total sample of the study consisted of one hundred $(\mathrm{N}=100)$ youth comprising male $(n=50)$ and female $(n=50)$ which were randomly selected from different areas of locality of Madhubani town - a well - known town of North Bihar. It is generally expected that the most affected group in our own nation India is youth especially in North Bihar region of Bihar State due to day today increasing unemployment. Thus, they have been found to spend most of the time with their friends and stay outside the home due to unemployment. They were bound to stay at home most of the time but no engagement with friends and with other social circles in the mean time. Hence, to achieve the target of the study, the intention of the present researchers was to study the levels of mental health in relation to stress of the particular group by using questionnaires schedules of Mental Health Scale developed by Jagdish and Srivastava (1983) and Perceived Stress Scale developed by Naik and Khan (2018) were used to collect the data from youths of Madhubani town. After collecting the information on the items of the schedules, the individual scores were obtained as per norms and procedures of the scales as given by authors and were given statistical treatment. Finally obtained results had shown that mental health and perceived stress variables are negatively correlated with each other among youth. Moreover, significant difference has been found on different dimensions of mental health and in total as well between the group of male and female youth belonging to Madhubani district. It is very interesting to note that male youth had scored higher degree on mental health schedule than female youth. Thus, the discrepancy of the obtained results has been discussed in detail by giving the probable reasons in the light of the activities prevailing now in Madhubani district of North Bihar, India.

Keywords: Mental Health, Stress, Youth, Madhubani and North Bihar, India.

Copyright () 2020 The Author(s): This is an open-access article distributed under the terms of the Creative Commons Attribution 4.0 International License (CC BY-NC 4.0) which permits unrestricted use, distribution, and reproduction in any medium for non-commercial use provided the original author and source are credited.

\section{INTRODUCTION}

Stress has become a part of our life in the present rapid changing scenario of human life. Thus, present era is called as era of stress. Due to stress life, every individual get affected at some extent. If we compare all the age groups of individuals we will find that most active and dynamic group is youth. It is generally seen that they spend most of the time outside the home (especially boys) with their friends and neighbours. So, there must be an influence on mental health of the individuals that is why researchers took an initiative to assess the level of mental health in correspondence with stress and considers the sample as youth.

\section{Mental Health}

Health is an important quality and indispensable condition for an organism to live one's life successfully. It is a very comprehensive concept as defined by the World Health Organization (WHO) "Health is a state of complete physical, mental and social well-being and not merely the absence of disease or infirmity" [1]. Hence, health is salubrious condition of body or mind that assists both the physical and mental conditions of individuals in doing the task reasonably and efficiently.

Husain and Khan [2] explained the term health refers to "more than physical health; it also connotes the individual's intrapsychic balance, the fit of his psychic structure with the external environment, and his social 
functioning". In their view point it isadvocated that health is a balanced state characterised by sound physical, emotional and social aspects of a person.

Thus, the concept of health goes beyond the proper functioning of the physical aspect only. According to Kappuswami [3] sound health includes active mind and controlled emotions. He further explained it as a state of being sane or wholesomeness of the body and mind which indicates that both the body and the mind are synergistic and work together efficiently and harmoniously. Thus the human being is an integrated psychosomatic unit whose conduct is determined and influenced by both physical and emotional factors.

From the above discussion three ideas are central and revolve around the concept of health: mental health is an integral part of health, mental health is not just the absence of illness and mental health is closely associated with one's physical health and behaviour. As The World Health Report [4] reported that "for all individuals, mental, physical and social health are vital strands of life that are closely interwoven and deeply interdependent. An understanding of this relationship grows; it becomes ever more apparent that mental health is crucial to the overall well-being of individuals, societies and countries". The concept of mental health is very comprehensive and it includes subjective wellbeing, self-efficacy, autonomy, competence, intergenerational dependence and self-actualisation of one's intellectual and emotional potential among others.

\section{Stress}

Stress is defined as a real or perceived imbalance between the environmental demands deemed essential for survival and an individual's gross capacity to adapt to these demands [5, 6]. As human beings survive through an ever evolving process of adaptation with respect to the requirements of an ever-changing environment, there exists a force which drives them to accomplish adaptation. Stress could also be understood as the pattern of negative physiological states as well as psychological responses often occurring in situations where individuals effectively perceive threats to their well-being, which they might be unable to meet.

The cognitive-phenomenological perspective, with its focus upon goal directed behavior, the selfinvolvement of human life and the conscious quality of human striving, offers a new conceptualization of stress. A person's life consists of the totality of their transactions with the environment and stress consists of those transactions with the environment which have not gone quite as that person wanted, planned and expected [7].

Various studies on stress have been conducted by different scholars of repute as stress occurs when individuals confront situations which are perceived as overwhelming and difficult to cope. Stress-related symptom means our body is giving us a warning signal that we are taking on too much. Everyone has a different response to stress. Likewise, every one may show a different sign or symptom of stress, depending on their temperament and life situation. It has become accepted wisdom that stress influences our physical and psychological health; more specifically, too much stress can make us ill. Thus, the notion that stress is bad for health and it can make us ill has become a modern cultural truism. Employment status of wives in India has been debated vastly, more specifically in northern India. There has been growing evidence that it affects self-esteem and psychological well-being of husbands in more than one way and often adversely.

It is important to mention that stress increases catecholamine and the increases the plasma catecholamine enhances platelet aggression, lowers the threshold to cardiac arrythminea, induces narrowing of the blood vessels and suppresses insulin secretion [8]. Stress related symptoms list was found in American Psychiatric Association's Diagnostic and Statistical Manual of Mental Disorders-IV, 1994 edition. They include the following physical signs on their stress related symptoms list such as: sleeplessness, sweaty palms, indigestion, sleep too much, fatigue, tight muscles, diarrhea, tight stomach pain, heart pounding, holding breath, skin breaks out, cold hands, shortness of breath, headaches and nausea. In India whatever researchers have so for been done in the area of stress, focuses basically on normal population [9, 10] with emphasis on work area stress. However, research in the area of patients stress is conspicuously absent.

\section{AIMS AND OBJECTIVES OF THE STUDY}

Having surveyed the review of literature on proposed research problem, it has been observed that various researches on stress and mental has been conducted in relation to different psycho-socio aspects but none of the studies have been found with particular reference to youth especially of Madhubani district. The sample area chosen for the present study is still an unexplored area. Thus, the findings of the study will fill the void of knowledge in area concerned. Thus, the present research work is of utmost value to understand the behavior of youth especially of Madhubani district of north Bihar, India. The following are the broad aims and objectives of the present study:

i. To study the relationship between stress and mental health among Youth.

ii. To study the mean differences of Stress among Male and Female Youth.

iii. To study the mean difference of Mental Health among Male and Female Youth.

\section{HYPOTHESES}

On the basis of the broad aims and objetives of the present study, the following hypothess were formulated: 
- Therewill be no relationship between stress and mental health among youth.

- There will be no mean differences of Stress among Male and Female Youth.

- There will be no mean differences of Mental Health among Male and Female Youth.

\section{RSEARCH METHODOLOGY Sample}

As per the sample of the study is concerned, researchers randomly selected one hundred youth $(\mathrm{N}=100)$ comprising male $(\mathrm{n}=50)$ and female $(\mathrm{n}=50)$ from different locality of Madhubani town - a well known town of Mithila region of North Bihar, India. Total subjects' age were ranged between 20 to 28 years.

\section{Tools and materials Used}

The following tools and materials were used for the present piece of research work:

\section{Perceived Stress Scale}

For measuring psychological stress among Youth - a scale developed and standardized by Naik and Khan [11] was used. The scale consists of 21 items on 5 -point Likert Scale with values anchored as $0=$ Not Stressed, 1=Slightly Stressed, 2=Mild Stressed, 3=Highly Stressed, and 4=Very Highly Stressed. The responses of each item varied from 0 to 4 . The score of the scale varies from 0 to 84 and can be interpreted as higher the score, the higher the stress. The reliability was determined by using Cronbach's Alpha and was found 0.93 as significant at.01 level of confidence. There are three factors of perceived stress and were labeled as traumatic stress, desolation, and agitation.

\section{Mental Health Inventory}

For measuring youth's mental health - a Mental Health Inventory developed and standardized by Jagdish and Srivastava [12] was used in the present research work. The scale comprised of 56 items (32 false keyed and 24 true keyed with six dimensions viz. self-evaluation (10 items), perception of reality (8 items), integration of personality (12 items), autonomy (6 items), group oriented attitudes (10 items) and environmental mastery (10 items).It is a 5 point Likert type responses, where subject has to choose from the category as labeled; Always, Very often, Sometimes, Rarely and Never. Marked responses are to be assigned for True keyed (positive statements) 5,4,3,2,1 and for False keyed (Negative statements) 1, 2, 3, 4, 5. The scale has a minimum score of 56 and maximum score of 280 , the neutral point is at 140 , scores below 140 indicates the poor mental health while scores above 140 reflects the good mental health.The reliability of the mental health inventory based on split half method was 0.73 . Further, the reliability was verified on the target sample and Cronbach's Alpha was found to be 0.87 , which confirms that the scale has a good reliability [13].
Descriptions of thedimensions of the inventory are as follows:

1. Positive Self-Evaluation (PSE): It includes self-confidence, self-acceptance, selfidentity, feeling of worth-whileness, realization of one's potentialities, etc.

2. Perception of Reality (PR): It is related to perception free from need distortion, absence of excessive fantasy and a broad outlook on the world.

3. Integration of Personality (IP): It indicates balance of psychic forces in the individual and includes the ability to understand and to share other people's emotions, the ability to concentrate at work and interest in several activities.

4. Autonomy (AUTNY): It includes stable set of internal standards for one's action, dependence for own development upon own potentialities rather than dependence on other people.

5. Group Oriented Attitudes (GOA): It is associated with the ability to get along with others, work with others and ability to find recreation.

6. Environmental Mastery (EM): It includes efficiency in meeting situational requirements, the ability to work and play, the ability to take responsibilities and capacity for adjustment.

\section{Biographical Information BlanK (BIB)}

Apart from the above tools, for tapping the personal information for interpreting the results, a biographical information blank was also self prepared. It includes - age, qualiication, family type, Parents' education (Mother and Father), number of family members, family income, area of locality (rural \& urban), etc.

\section{Procedure}

The above three materials viz., youth's mental health schedule, youth's perceived stress scale and, biographical information blank were in printed form and were administered individually on all selected youths. All the selected youths of Madhubani town were assured by taking them into confidence that provided information will be kept strictly confidential and the information provided by you will be used for research purposes only. Having collected the responses to the items of the scales, they were scored according to the procedures of the scales and the individual scores were obtained for giving statistical treatment and finally presented in the tables.

\section{RESULTS AND DISCUSSIONS}

As the results obtained and presented in the tables have been discussed that follows: 
Table-1: Showing Correlation between Stress and Mental Health as well as on its Different Dimensions

\begin{tabular}{|l|l|l|l|l|l|l|l|}
\hline & $\begin{array}{l}\text { Self- } \\
\text { evaluation }\end{array}$ & $\begin{array}{l}\text { Perception } \\
\text { of reality } \\
\text { of } \\
\text { personality }\end{array}$ & $\begin{array}{l}\text { Integration } \\
\text { Autonomy }\end{array}$ & $\begin{array}{l}\text { Group } \\
\text { Oriented } \\
\text { attitude }\end{array}$ & $\begin{array}{l}\text { Environmental } \\
\text { Mastery }\end{array}$ & $\begin{array}{l}\text { Total } \\
\text { Mental } \\
\text { Health }\end{array}$ \\
\hline $\begin{array}{l}\text { Perceived } \\
\text { Stress }\end{array}$ & $-.599 * *$ & $-.611^{* *}$ & $-.575^{* *}$ & $-.224 * *$ & $-.684 * *$ & $-.568^{* *}$ & $-.729 * *$ \\
\hline $\begin{array}{l}\text { Level of } \\
\text { Significance }\end{array}$ & .000 & .000 & .000 & .000 & .000 & .000 & .000 \\
\hline
\end{tabular}

Table-1 shows that all the dimensions of mental health as well as mental health itself significantly and negatively correlated with stress. It means that the dimensions entitled Self-evaluation ($.599, p<.01)$, Perception of reality $(-.611, p<.01)$, Integration of personality $(-.575, p<.01)$, Autonomy (-
$.224, p<.01)$, Group Oriented Attitude (-.684, $p<.01)$, Environmental Mastery (-.568, $p<.01)$ and Overall Mental Health (-.729, $p<.01)$ are adversly correlated with Perceived Stress. As per the finding, when Perceived Stress increases Mental Health decreases and vice-versa.

Table-2: Showing Mean Difference of Perceived Stress among Male $(n=50)$ and Female $(n=50)$ Youth of Madhubani District of Mithila Region of North Bihar, India

\begin{tabular}{|l|l|l|l|l|l|}
\hline Variable & Group & Mean & SD & t-value & Sing. \\
\hline Perceived Stress & Male & 11.00 & 2.030 & 13.556 & .000 \\
\cline { 2 - 4 } & Female & 18.98 & 3.634 & & \\
\hline
\end{tabular}

Table-2 exhibits that Male and Female both are significantly differ at Perceived Stress as $t-13.556$ has been found statistically significant at .01 level of confidence, whereas, from the Table-2, it could be observed that female participants are bearing higher level of stress as compared to their male counterpart as obtained mean score of female perceived stress is 18.98 with an SD - 3.634 in comparison to male as perceived stress is low i.e. mean score obtained on stress by male is 11.00 with an SD 2.030 . It means that female candidates are more influences with stress as compared to Male candidates. The formulated hypothesis i.e. there will be no significant difference between male and female youth in terms of perceived stress, stands rejected. The results seem to be logical that female are more curious than male to change their lifestyle pattern in accordance with the needs of the hour. Moreorever, it is also observed that females are doing hard work by the means of education to get empowered. It is because of the fact that education is one of the important tools by which everyone can get their life satisfied. The present era is totally based on high modern technology where every men and women are running to compete each other in the job market. Hence, it is assumed that female youths are found to be stressful especially from where the present piece of research work has been completed. The presented results can also be observed by the following chart:

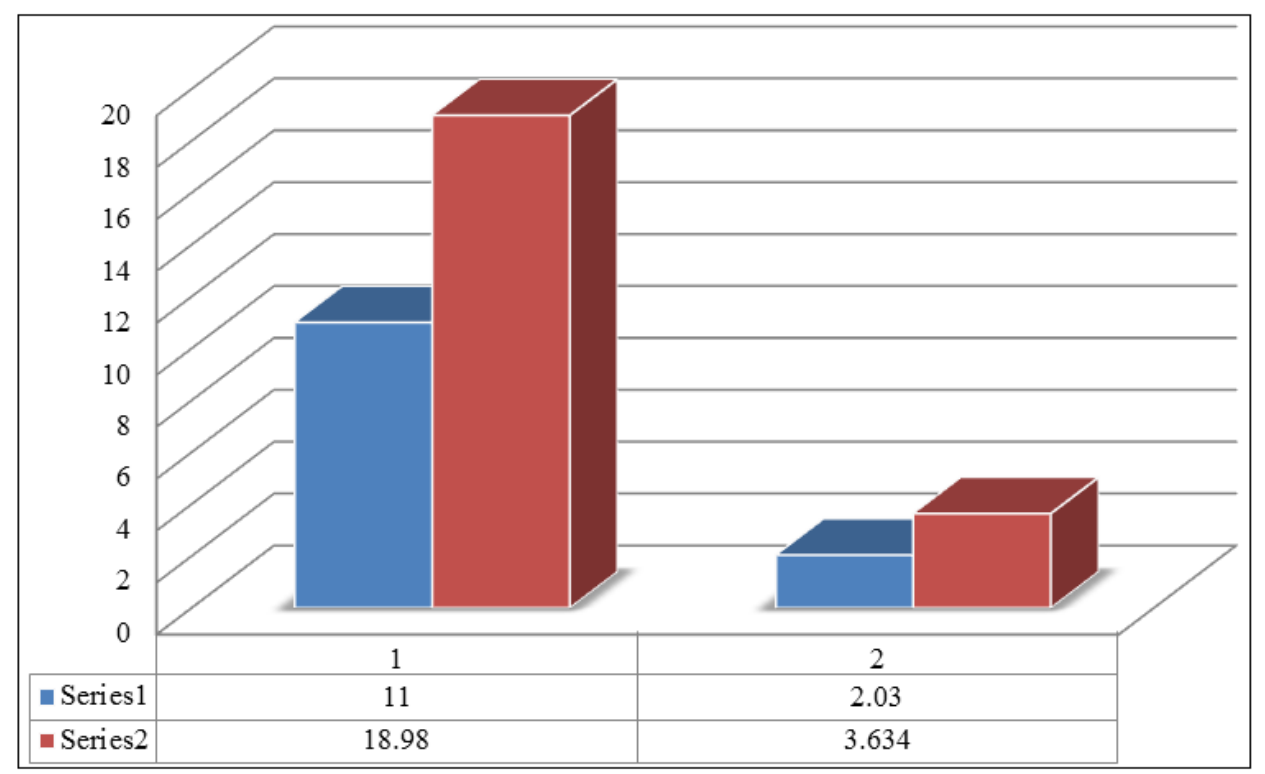

Chart-1: Showing Mean and SD of Male (Series-1) and Female (Series-2) of Perceived Stress among Youth 
Table-3: Showing Mean Differences of Mental Health as well as of its Different Dimensions among Male (n=50) and Female $(\mathbf{n}=50)$ Youths

\begin{tabular}{|l|l|l|l|l|l|}
\hline Variable & Group & Mean & SD & t-value & Sing. \\
\hline Self-evaluation & Male & 21.00 & 2.020 & 9.849 & .000 \\
\cline { 2 - 5 } & Female & 17.60 & 1.370 & & \\
\hline Perception of rality & Male & 21.40 & 2.080 & 11.049 & .000 \\
\cline { 2 - 5 } & Female & 18.00 & .639 & & \\
\hline Integration of Personality & Male & 26.20 & 2.814 & 10.895 & .000 \\
\cline { 2 - 5 } & Female & 21.20 & 1.616 & & \\
\hline Autonomy & Male & 18.60 & 2.080 & 3.169 & .002 \\
\cline { 2 - 4 } & Female & 17.60 & .808 & & \\
\hline Group Oriented Attitude & Male & 23.20 & 1.738 & 12.250 & .000 \\
\cline { 2 - 4 } & Female & 19.00 & 1.690 & & \\
\hline Environmental Mastery & Male & 23.60 & 2.603 & 7.800 & .000 \\
\cline { 2 - 4 } & Female & 19.00 & 3.258 & & \\
\hline \multirow{2}{*}{ Mental Health Total } & Male & 134.00 & 8.031 & 17.007 & .000 \\
\cline { 2 - 4 } & Female & 112.40 & 4.020 & & \\
\hline
\end{tabular}

Table-3 exhibits that male and female differ at every dimension of mental health as well as Overall Mental Health. As per the results of Table- 2 shows that female candidates are more influenced by stress, it's again verified by the result of Table-3; where findings shows that male candidates scored higher on mental health than female participants at each dimensions of mental health.

At Self-evaluation dimension male scored 21.00 while female candidates scored 17.60, Perception of reality dimension male scored 21.40 while female candidates scored 18.00, Integration of Personality dimension male scored 26.20 while female candidates scored 21.20, Autonomy dimension male scored 18.60 while female candidates scored 17.60, Group Oriented Attitude male scored 23.20 while female candidates scored 19.00, Environmental Mastery male scored 23.60 while female candidates scored 19.00 and at Overall Mental Health, male scored 134.00 while female candidates scored 112.40 .

As per the findings of the study, it's crystal clear that male candidates are bearing better on mental health as compared to their female counterpart especially in Madhubani district from where the present piece of research work has been carried out.

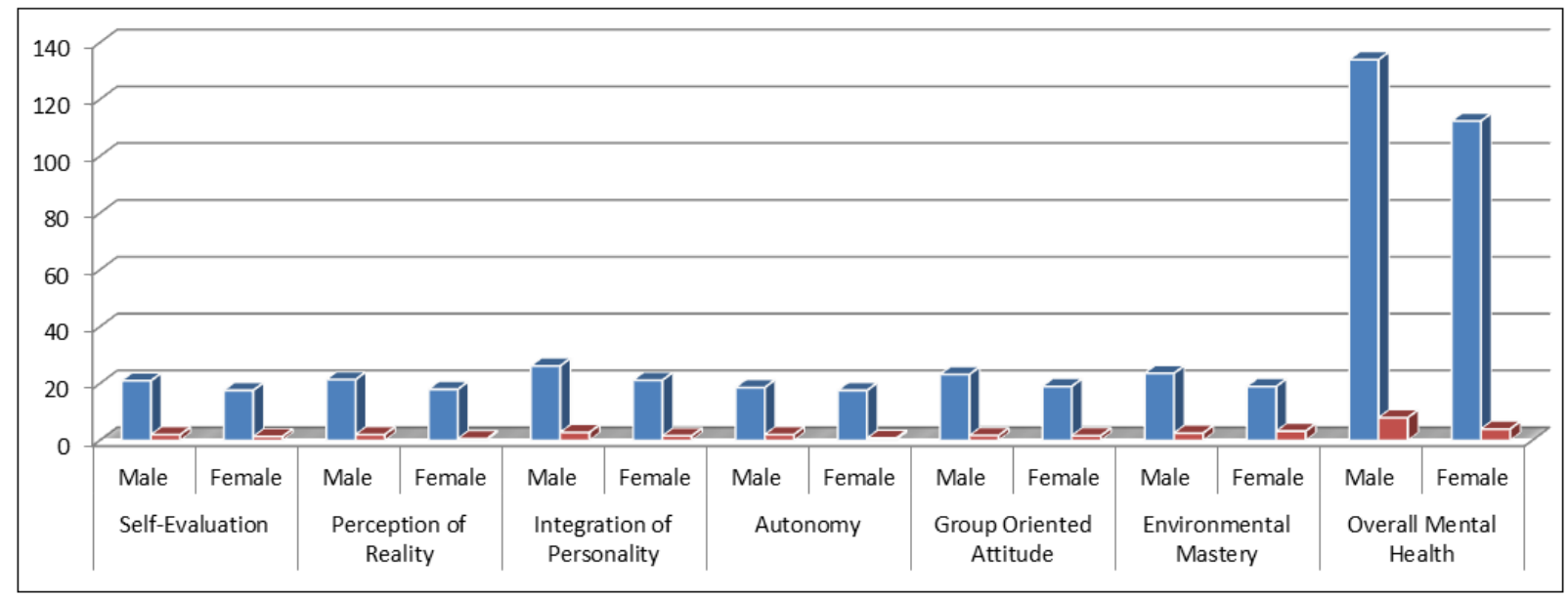

Chart-2: Shows Mean and SD of Male (Series-1) and Female (Series-2) of Menral Health and it's different dimensions among Youth

On the basis of the obtained results and its interpretation is that we might feel physical stress which is the result of too much to do, not enough sleep, a poor diet or the effects of an illness. Stress can also be mental: when we worry about money, a loved one's illness, retirement, or experience an emotionally devastating event, such as the death of a spouse or being fired from work. However, much of our stress comes from less dramatic everyday responsibilities. Obligations and pressures which are both physical and mental are not always obvious to us. In response to these daily strains our body automatically increases blood pressure, heart rate, respiration, metabolism, and blood flow to our muscles. This response, is intended to help our body react quickly and effectively to a highpressure situation [14]. 
It is important to point out that when we are constantly reacting to stressful situations without making adjustments to counter the effects, we will feel stress which can threaten our health and well-being.It is essential to understand that external events, no matter how we perceive those events which may cause stress. Stress often accompanies the feeling of "being out of control."

Consequently, we can say that hypothesis-1 i.e. "There will be no relationship between stress and mental health among youth." is get rejected as findings of the study have shown that both variables are significantly and negatively correlated with each other. It was also found that female participants are experiencing more stress than male participants (Table$1)$.

Secondly, hypithesis- 2 i.e. "There will be no mean differences of Stress among Male and Female Youth." is also rejected and findings of the study exhibits that male and female participants are significantly differ in terms of their perceived stress level (Table-2).

Finally hypothesis -3 i.e. "There will be no mean differences of Mental Health as well as on its dimensions among Male and Female Youth." is also rejected. It means that male and female both are significantly differ at the level of mental health as well as on its different dimensions (Table-3).

\section{CONCLUSIONS AND SUGGESTION}

On the basis of the obtained results and its interpretations the following conclusionshave been drawn:

1) Negative correlationship have been found between stress and mental health among youth especially in Madhubani district from where the present piece of research work has been carried out.

2) Significant difference has been found between male and female youth interms of their degree of stress.

3) Significant difference has also been found between male and female youth on their degree of mental health.

4) In all the dimensions of mental health, namely, 'Self - Evaluation'; 'Perception of Reality'; 'Integration of Personality'; 'Autonomy'; 'Group - oriented Attitude'; and 'Environmental Mastery' has been found significant difference between male and female youth in madhubani diatrict of Mithila region, although, male scored higher degree of mental health as compared to female youth.

5) Finally, observations have revealed the fact that the youths (male and female) living in Madhubani district of Mithila region are found more cultured, even female youth also scored above average level as compared to male but significant difference has been found in terms of their degree of mental health and perceived stress, although, female have been found more prone to stress. Thus they differ in accordance with the situations like increasing unemployment day by day and other lifestyle patterns of life which being modernized based on hi-info-tech society.

6) Thus, it is suggested that parents, social institutions, local government must check the activity of youths (male and female) in all respect time to time. It is because of the fact that our youths are backbone of the nation India. They should be given all perks and benefits in terms of their career building for nation's building development, process and communication. Hence, the psychological services in terms of career and guidance counseling especially to all youths are suggested in all the districts of India.

\section{REFERENCES}

1. World Health Organization. (2003). Investing in Mental Health (20). Geneva. Retrieved fromhttp://www.who.int/mental_health/media/investing _ mnh.pdf

2. Husain, A., \& Khan, S. (2013). Determinants of Mental Health: A New Interpretation. In Hooda, D., \& Sharma, N. R. (Eds.) Mental Health-Risk and Resources (pp. 1-19), New Delhi: Global Vision Publishing House. ISBN: 978-81-8220582-6

3. Kuppuswamy, B. (1993). Advanced Educational Psychology, New Delhi: Sterling Publishers.

4. The World Health Report. (2001). Mental Health: New Understanding, New Hope. Geneva, World Health Organization. Retrieved from: http://www.who.int/whr/2001/en/whr01_en.pdf

5. Lazarus, R. S. \&Folkman, S. (1984). Stress, Appraisal and Coping. New York: Springer.

6. Chrousos, G. P. (2009). Stress and Disorders of the Stress System. Nature Reviews Endocrinology, 5 , 374-381. http://dx.doi.org/10.1038/nrendo.2009.106.

7. Bartlett, D. (2010). Stress perspective and processes. In Payne, S., \& Horn, S. (Eds.), Health Psychology Series, New Delhi: Tata McGraw Hill Education Private Limited.

8. McEween, B. S. \&Sellar, E. (1993). Stress and the individual: Mechanism leading to disease. Archives of International Medicine, 153, 2093 2101.

9. Saxena, S., Nepal, M. K., \& Mohan, D. (1982). DSM-III Axis 1 diagnoses of Indian psychiatric patients with somatic symptoms. American Journal of Psychiatry, 145, 1023-1024.

10. Sharma, I., \& Ram, D. (1986). Life events and support systems in anxiety state. Indian Journal of Psychiatry, 2, 357-367. 
11. Naik., and Khan (2019). 'Perceived Stress Social Support and Psychological Capital as Predictors of Post Traumatic Growth among Youth.' Department of Psychology, Aligarh Muslim University, Aligarh, Unpublished Thesis.

12. Srivastava, J. N. (1983). Literacy, Education, and Demographic Behaviour: Some Salient Findings from PRC Studies. Population Research Centre, Department of Economics, Lucknow University.

13. George, D., \&Mallery, M. (2003). Using SPSS for Windows step by step: a simple guide and reference.

14. Mental Health America. (2020). Retrieved from https://www.mhanational.org/conditions/stress. 